\title{
Compliance and Organizations - How Can Organizations Enable Compliance?
}

\author{
Corinna Elisabeth Gierl \\ SMBS - University of Salzburg Business School, Austria; \\ University of Latvia, Latvia
}

\begin{abstract}
The importance of compliance for companies is obvious, as compliance violations can have farreaching consequences. Numerous scandal reports in press testify the general interest of society in compliance. The question arises, how companies can promote compliance in organizations. Up to now, too little attention seems to be paid to a current and comprehensive overview of compliance drivers in organizations. This gap is addressed by providing a systematic literature review (SLR) on factors that enable compliance within an organization. The 7-S framework of organizations, developed by Waterman et al. (1980) responds to the problem of multiplicity of factors that also need to be considered when implementing compliance in organizations and was therefore used as the theoretical underpinning of this paper. The results of this SLR show, that there are already various starting points for "hard" and "soft" organizational success factors of compliance in the individual areas of an organization. Especially "soft" organizational factors, such as culture, staff and organizational skills seem to be important for long term success in compliance. This paper is not only relevant for compliance officers and compliance responsible persons, but also for compliance researchers, as several limitations demonstrate the need for further qualitative and quantitative research.
\end{abstract}

Keywords: compliance, success factors, organization, systematic literature review 


\section{Introduction}

Compliance is a topic that is currently addressed in specific economical contexts. Literature covers tax compliance (Araújo Marques et al., 2020; D'Attoma et al., 2020; Li et al., 2020; Robbins and Kiser, 2020), trade compliance (Baier et al., 2020), compliance with labor regulations (Dávalos et al., 2020) and labor standards (Pike, 2020), reporting standards (Tsalavoutas et al., 2020) and also islamic shariah compliance (Farooq and Pashayev, 2020; Ismail et al., 2020; Satt et al., 2020). The body of current literature on compliance also investigates IT security and data governance (Johannsen et al., 2020) as well as the impact of several factors on IT or information security compliance, such as different communication approaches (Barlow et al., 2018) and the role of leadership (Feng et al., 2019; Paliszkiewicz, 2019). With regard to compliance, researchers often refer to business scandals, not only to show the impact that compliance violations can have, but also to emphasize the importance of compliance (Burdon and Sorour, 2020, p. 49; Enciso et al., 2017, p. 71; Fotaki et al., 2020, p. 19; Quick and Sayar, 2020, p. 15).

An interesting description of compliance in the context of corporate governance is its function to prevent risk by the enforcement of practices and points out that "compliance is primarily a quantitative issue" (Fotaki et al., 2020, p. 23). This description of compliance seems to contradict the above-mentioned compliance violations, since compliance in organizations probably requires more than a mere quantitative approach. Several studies have already addressed the relevance of social or normative motives for compliance (Nielsen and Parker, 2012; Winter and May, 2001) and also organizational commitment is considered to have impact on compliance (Celis, 2018). Parker and Nielsen (2009) also examined the relationships between the implementation of compliance management system, compliance management in practice and compliance, highlighting the importance of management commitment to compliance values as well as managerial supervision and organizational resources and pointed out, that also the size of the organization matters. These papers demonstrate the complex nature of compliance in organizations and outlines the number of factors that must be considered by companies when implementing compliance.

In fact, organizations need an in-depth knowledge of efficient compliance measures and how to implement them. The identification of concrete compliance enablers represents a major contribution to current compliance research and could set up future research priorities that would need to be researched in more detail. In practice, this knowledge of compliance drivers also plays a vital role in the targeted use of resources and the improvement of compliance management and could result in the implementation of new compliance measures in organizations.

As previously described, researchers currently focus on specific areas of compliance or on the impact of dedicated factors on compliance. The results of a keyword search in the Scopus database show, that there are several literature reviews on compliance in medicine, but hardly any contributions on the topic of business, management and economics, which are listed in detail in appendix A. The latest literature reviews on management of business process compliance requirements (Mustapha et al., 2020) or compliance with international financial reporting standards (Tsalavoutas et al., 2020) can barely be applied to general compliance management in organizations. 
Up to now, too little attention seems to be paid to a current and comprehensive overview of compliance drivers although this is of great interest for science and practice. Especially the examination of compliance in the context of organizations and organizational behavior seems to be important, as compliance management must be implemented by organizations, which is why compliance should be aligned with the needs and existing resources of organizations to be particularly effective and simple to implement. To make the issue even more challenging, „organizations are complex systems” (Jensen, 1983, p. 325). There may be some compliance success factors that are difficult for organizations to implement and therefore less effective than others. Organizations need precise and content-related implementation guidelines for compliance success factors. It is essential to align compliance management with the specifics of organizations, as this seems the only way to flexibly respond to new increasing legal or customer-specific compliance requirements. This shows that both areas, the behavior and functioning of organizations as well as the drivers of compliance must be analyzed in detail and applied to each other.

This gap is addressed by providing a systematic literature review (SLR) on factors that enable compliance within an organization. The purpose of this paper is to review recent research regarding factors that determine compliance performance in organizations, aiming to identify key drivers of compliance within organizations. This paper aims to provide an overall overview of compliance factors as a starting point for further research to develop an integrative and holistic approach of compliance management for organizations. The following question will be addressed: Which compliance drivers in organizational context have been identified in the literature? In addition, a brief outlook on future research needs referenced in literature will be provided.

As described above, compliance is subject to several different disciplines. Throughout this paper and particularly with regard to the SLR, the term compliance refers to general adherence to rules and standards and includes aspects that could generally be applied to organizations to adopt an unbiased approach and not to miss potential insights. To answer the research question this paper is organized as follows. Section 2 refers to the theoretical organizational background, as the 7-S framework according to Waterman et al. (1980) is the theoretical underpinning for this research study. Section 3 describes the methodology applied to conduct the SLR. The results of the SLR are presented in section 4 . The paper is completed with discussing the key findings and its deriving implications, as well as the limitations and further research requirements. 


\section{Theoretical background}

Literature on compliance is based on different theories depending on the research focus. Especially with regard to the interaction between two parties or with focus on the individual, some researchers refer, among other theories, to the agency theory like Handayani and Ibrani (2019) or Zulfikar et al. (2020), others use the expectancy theory, e.g. Enciso et al. (2017) or the theory of planned behavior and rational choice theory like Bulgurcu et al. (2010). Other papers are based on more general approaches as the institutional theory (e.g. Burdon and Sorour, 2020).

Also this study follows a rather common theoretical approach. Waterman et al. (1980, p. 16) argue, that organizations are not able to make rational decisions, due to complexity and number of different needs, which is why a single approach such as organizational structure may not be sufficient to change an organization in the most effective way. Waterman et al. (1980, pp. 17-18) developed a new organizational framework which does not only help to identify organizational weaknesses, but also provides a starting point for improvement by attributing the effectiveness of an organization and its ability to change to several different factors and especially their relationship to each other - structure, strategy, systems, style, skills, staff, and superordinate goals, shown in figure 1 .

Figure 1: A New View of Organization

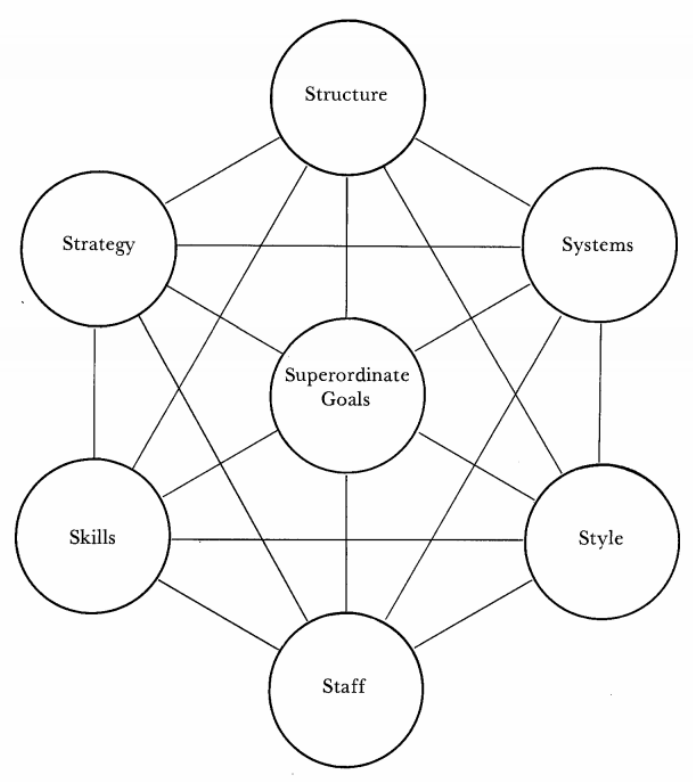

Source: Waterman et al., 1980, p. 18 
The model highlights the connection of each factor with each other and the non-hierarchical structure of the elements, which means that in order to achieve change or progress, all factors must be taken into account, whereby depending on the case, single factors could be identified as key drivers (Waterman et al., 1980, pp. 18-19). The 7-S framework addresses the complexity by defining individual factors that become workable as a result (Waterman et al., 1980, p. 18). The theoretical model of Waterman et al. (1980, p. 18) responds to the issue of "multiplicity of factors" to be considered, also when implementing compliance in organizations, which was discussed in the introduction. For this reason and since the model can be used as a supportive structure for categorizing the results of the SLR, the model was used as the theoretical basis for this paper. In the following, the single elements are discussed in detail and applied to the research topic to develop a better understanding of the theoretical contribution of the model to the research subject.

Structure - According to Waterman et al. (1980, p. 19) structure coordinates divided tasks and considers specialization versus integration and decentralization versus recentralization. Structure applied to the implementation of compliance in organizations, leads to the important insight, that the structural organization of compliance departments must be well considered. Departments working on compliance-related tasks, such as setting up new compliance processes, monitoring, auditing, incident management and training organization etc. could be either structured as a specialized and centralized department or organized following the integrated and decentralized approach, e.g. establishing compliance delegates in different departments. With regard to structures, also size and complexity of the company must be taken into account (Waterman et al., 1980, p. 19).

Strategy - Waterman et al. (1980, p. 20) explain strategy as the way of how a company reacts to changing external influences such as customers and competitors, as the plan a company follows to optimize its situation compared to competitors by focusing on generating "unique value", which additionally may have positive influence on building structures. With regard to compliance, legal compliance requirements or requests from customers and other stakeholders can be seen as such external influences. Thus, compliance must be integrated and clearly formulated in a corporate strategy, as it may represent a competitive advantage.

Systems - can be understood as formal and informal processes to manage and complete tasks in different contexts and have to be considered as a very important element, as organizational changes can be triggered by changes in the systems, even without major restructuring measures (Waterman et al., 1980, p. 21). This means the setup of compliance processes may be a simple starting point to implement compliance in organizations. Especially formal processes could be recorded in written operating procedures or codes of conduct.

Style - refers to company's culture implemented as action patterns and symbolic behavior through extensive internal communication and is key to enable organizational change or performance (Waterman et al., 1980, p. 22). Patterns of action regarding compliance will probably develop over time. Therefore, a compliance culture in organizations seems to be particularly important, which should be promoted by the exemplary behavior of the top management as well as by appropriate communication throughout the organization.

Staff - According to Waterman et al. (1980, pp. 23-24) staff or people should be seen as resources that need to be taken care of, as well as developed and deployed, considering hard aspects (e.g. 
appraisal systems or training) but also soft aspects (e.g. behavior and attitude). When applying this element to compliance, it seems that the "soft" factors in contrast to the "hard" aspects could be more decisive to establish compliance within an organization. The aim of compliance in organizations is compliant behavior of the staff, which is why organizations should focus on building and motivating the right attitude of the employees, supported by "hard" aspects.

Skills - can be understood as prominent qualities, whereas phasing out old skills and at the same time reorganizing resources and developing new skills may be a challenge (Waterman et al., 1980, p. 24). Increased legal requirements and the rising attention of compliance may indicate the necessity to develop compliance skills to one of the main characteristics of an organization, as it may also reflect a competitive advantage. The capability to establish effective compliance management systems could be mentioned as an example.

Superordinate goals - when talking about superordinate goals, Waterman et al. (1980, pp. 24-25) mean the primary orientation and future focus of a company, based on "main values", which means more than the official company targets. Compliance should be integrated into the future orientation of the company and thus should not stand in competition with the other objectives. Whether compliance is a superordinate goal, probably depends on the current situation of organizations, e.g. after severe compliance violations.

\section{Methodology - a systematic literature review (SLR)}

Before empirically researching a topic, Xiao and Watson (2019, p. 94) recommend conducting a systematic review. This statement supports the approach used in this paper to analyze and assess current research about compliance in organizations to find compliance drivers and further research requirements. The results and insights of this paper could be used as a starting point for further empirical studies. Although there is a development towards a structured literature review, which according to Massaro et al. (2016, p. 769) is that type of literature review, that has the most strict rules, a systematic literature review (SLR) was chosen for this paper, as a SLR appears to be a reliable approach of literature reviews in current research that can be applied to a variety of different areas. As the name already suggests, a SLR follows a systematic procedure and "is based on a clearly formulated question, identifies relevant studies, appraises their quality and summarizes the evidence by use of explicit methodology“" (Khan et al., 2003, p. 118). Fink (2020, p. 6) provides a well-known definition of a SLR: ,a research literature review is a systematic, explicit, and reproducible method for identifying, evaluating, and synthesizing the existing body of completed and recorded work produced by researchers, scholars, and practitioners". The most important features of literature reviews are therefore validity, reliability and repeatability (Xiao and Watson, 2019, p. 93).

As this paper uses the SLR as a main research method, the review can be characterized as a "standalone systematic literature review" (Okoli, 2015). Although there are various guidelines for conducting an SLR, that suggest different numbers of conducting steps, the core points to be considered seem to be remarkably similar (e.g. Khan et al., 2003, Okoli, 2015, Xiao and Watson, 2019). The particularly comprehensive approach with eight successive steps according to Okoli (2015, pp. 883-884) has been chosen for this paper, as these steps are relevant for any kind of scientific literature reviews: (1) identify the purpose, (2) draft protocol and train the team, (3) apply 
practical screen/screening for inclusion, (4) search for literature, (5) extract data, (6) appraise quality/ screening for exclusion, (7) synthesize studies, (8) write the review. These steps will be described and applied to the research topic.

Purpose of the SLR - Purpose of this SLR is to systematically evaluate the existing body of literature to identify success factors for the specific areas of an organization that are inherent to the needs and characteristics of organizations. The SLR is the starting point, to become aware of the aspects already dealt with in the current literature, to check which precise recommendations for implementing effective compliance measures already exist, to build on these and to identify further research requirements.

Draft protocol and train the team - As this SLR is conducted without participation of other reviewers, this step can be neglected. This section describes in detail how the SLR was conducted and can be considered as a kind of protocol.

Practical screen/screening for inclusion - In this central step, it is determined and justified which literature contributions are to be considered and which are to be omitted, without the review losing comprehensiveness (Okoli, 2015, p. 884). Purposeful inclusion parameters were defined when conducting this SLR. The keyword search was conducted by using the database Scopus, which should not show any relevant differences to other databases, especially since some researchers use Scopus, considering the database as most relevant for their literature review in management science (e.g. Woschank et al., 2020). The contributions in Scopus are peer-reviewed, which additionally increases the quality of the SLR.

To get an impression of the magnitude of the current literature on the subject, contributions on compliance were first evaluated by screening the title, abstract and keywords for "compliance" without further restrictions. This first screening results in 418,570 contributions, however the distribution of these contributions among the subject areas is quite revealing and shows that the subject area of business, management and accounting is mentioned only in the 11th order with 12,384 contributions. This means compliance is strongly addressed in other disciplines, especially in medicine and related areas such as biochemistry, pharmacology, nursing, but also in engineering, social sciences, computer sciences or even in environmental science, materials science and psychology. In order to further develop an appropriate search strategy with relevant inclusion criteria for the actual SLR with regard to compliance in business organizations, it was helpful to review the keywords of the subject area "business, management and accounting" and "economics, econometrics and finance". For this purpose, the contributions of the mentioned subject areas of the last 10 years, limited to articles, conference papers, reviews and conference reviews were analyzed. 


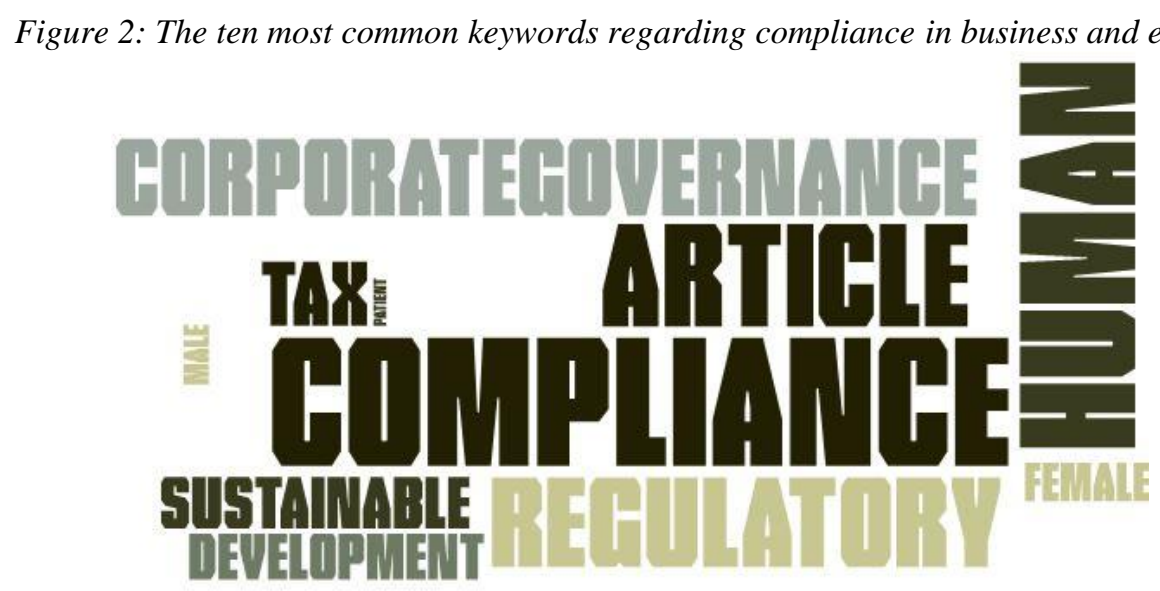

Source: Figure created by the author

As shown in figure 2, it is apparent that the key words of these literature contributions hardly relate to the research question of this paper. Even with limitation to relevant subject areas, the keyword compliance without any further addition is too general for the objective of this paper, since compliance is to be examined in the context of organizations. At this point, the broad meaning of compliance becomes clear. "Corporate governance" seems to be the only keyword that may be relevant for this paper. However considering its definition, corporate governance tends to focus on shareholders and their interests (Süsi and Lukason, 2019, p. 704; Tirole, 2001, p. 1). This contrasts with the goal of this study, which follows a general approach with an internal focus on the organization.

A second run with compliance as part of the title shows keywords that do not necessarily fit the topic either, but still have some relevance, which was not the case with some of the keywords in the run described above. The results suggest using the keyword compliance only with a specific reference to organizations and as certain part of a title. For this reason, it was decided to include organiz* in addition to compliance to conduct a SLR targeted to the research question. As success factors or effective measures of compliance should be identified by the SLR, different key words describing this circumstance and synonyms were defined. In addition, the literature research on keywords regarding success factors is extended not only to titles but also to abstracts and keywords in order to achieve comprehensive results. To get as many hits as possible regardless of the ending of the keywords, the *-function of the database was used. As further inclusion criteria to ensure quality, only articles, conference papers and reviews will be considered. In order to obtain up-todate, yet comprehensive results, contributions from 2010 to the date of conduction of the SLR (December 2020), are included in the SLR. The defined language of the contributions used is English. Furthermore, as compliance is a commonly used term, only the subject areas "business, management and accounting" as well as "economics, econometrics and finance" related to the research context were considered. Table 1 provides an overview of the inclusion criteria used for the SLR. 
Table 1: SLR inclusion criteria

\begin{tabular}{|c|c|c|c|c|c|}
\hline $\begin{array}{l}\text { Keyword } 1 \\
\text { (in title) }\end{array}$ & $\begin{array}{l}\text { Keyword } 2 \text { (in title, abstract, } \\
\text { keyword) }\end{array}$ & Language & $\begin{array}{l}\text { Type of } \\
\text { paper }\end{array}$ & $\begin{array}{l}\text { Considered } \\
\text { time frame }\end{array}$ & Subject area \\
\hline $\begin{array}{l}\text { organiz* } \\
\text { compliance }\end{array}$ & $\begin{array}{l}\text { factor*, impact*, success, } \\
\text { enable*, promot*, } \\
\text { influence*, effect*, foster*, } \\
\text { strength*, optimiz*, affect* }\end{array}$ & English & $\begin{array}{l}\text { article, } \\
\text { conference } \\
\text { paper, } \\
\text { review }\end{array}$ & $2010-2020$ & $\begin{array}{l}\text { Business, } \\
\text { Management and } \\
\text { Accounting; } \\
\text { Economics, } \\
\text { Econometrics and } \\
\text { Finance }\end{array}$ \\
\hline
\end{tabular}

Source: Table created by the author

Search for literature \& extract data - After defining the inclusion criteria, the relevant literature was searched, using the following query string:

( TITLE ( organiz* AND compliance ) AND TITLE-ABS-KEY (factor*) OR TITLE-ABS-

$K E Y$ ( impact*) OR TITLE-ABS-KEY ( success ) OR TITLE-ABS-KEY (enable*) OR TITLE-ABS-

$K E Y$ ( promot*) OR TITLE-ABS-KEY (influence*) OR TITLE-ABS-KEY ( effect*) OR TITLE-ABS-

$K E Y$ ( foster*) OR TITLE-ABS-KEY ( strength*) OR TITLE-ABS-KEY (optimiz*) OR TITLE-ABS-

KEY (affect*)) AND PUBYEAR > 2009 AND (LIMIT-TO (DOCTYPE, "ar" ) OR LIMIT-

TO ( DOCTYPE, "cp" ) OR LIMIT-TO ( DOCTYPE, "re" )) AND ( LIMIT-

TO ( SUBJAREA, "BUSI" ) OR LIMIT-TO ( SUBJAREA, "ECON" ) ) AND ( LIMIT-

TO ( LANGUAGE, "English" ))

As a result, 40 contributions were found and the available data and abstracts were extracted for further reviews.

Appraise quality/screening for exclusion - The selected contributions were reviewed and evaluated to what extent they can contribute to the key research question. The most important criterion at this point was the correct researched cause-effect relationship. It had to be clearly recognizable that the influence of various factors or criteria on compliance were investigated and therefore create a reference to success factors. Another criterion was the organizational context of the studies. The results of the papers had to be at least hypothetically applicable to a general organizational context, which is why a too specific context of compliance or a too specific research environment was excluded, e.g. compliance with the World Health Organization's farm-based multiple-barrier approach (Amponsah et al., 2016), halal compliance (Baharuddin and Ismail, 2018) or supplier social compliance (Jajja et al., 2019). To keep the quality of the SLR high, relevant contributions should at least use one qualitative or quantitative research method.

The appropriateness of the papers was categorized in high, medium and low appropriateness as well as exclusion, based on the criteria described above. After reviewing the titles and abstracts of the literature, three highly appropriate papers, 12 medium appropriate and four low appropriate papers were identified. 21 contributions could be excluded for further consideration of this research work. With regard to the intended quality of the SLR, it was decided not to examine low appropriate studies but to include medium appropriate studies in addition to the highly appropriate studies for further analysis. The medium appropriate studies include several studies regarding information security or similar subjects. They were considered for this SLR, as they contain aspects, which could be transferred to the general organizational context in an adapted form. Furthermore, information security compliance is not too specific, especially since most organizations have to deal with information security. One medium appropriate paper could not be 
accessed in full text ${ }^{1}$, which is why 14 papers were analyzed in detail. The last two steps of an SLR "synthesize studies" and "write the review" will be summarized in the following section. 


\section{Results}

\subsection{Descriptive results}

14 relevant papers could be identified, three papers (21\%) are considered as highly appropriate, 11 contributions (79\%) are rated to be medium appropriate. A detailed list is provided in table 2 .

Table 2: Summary of identified papers and sources grouped by appropriateness

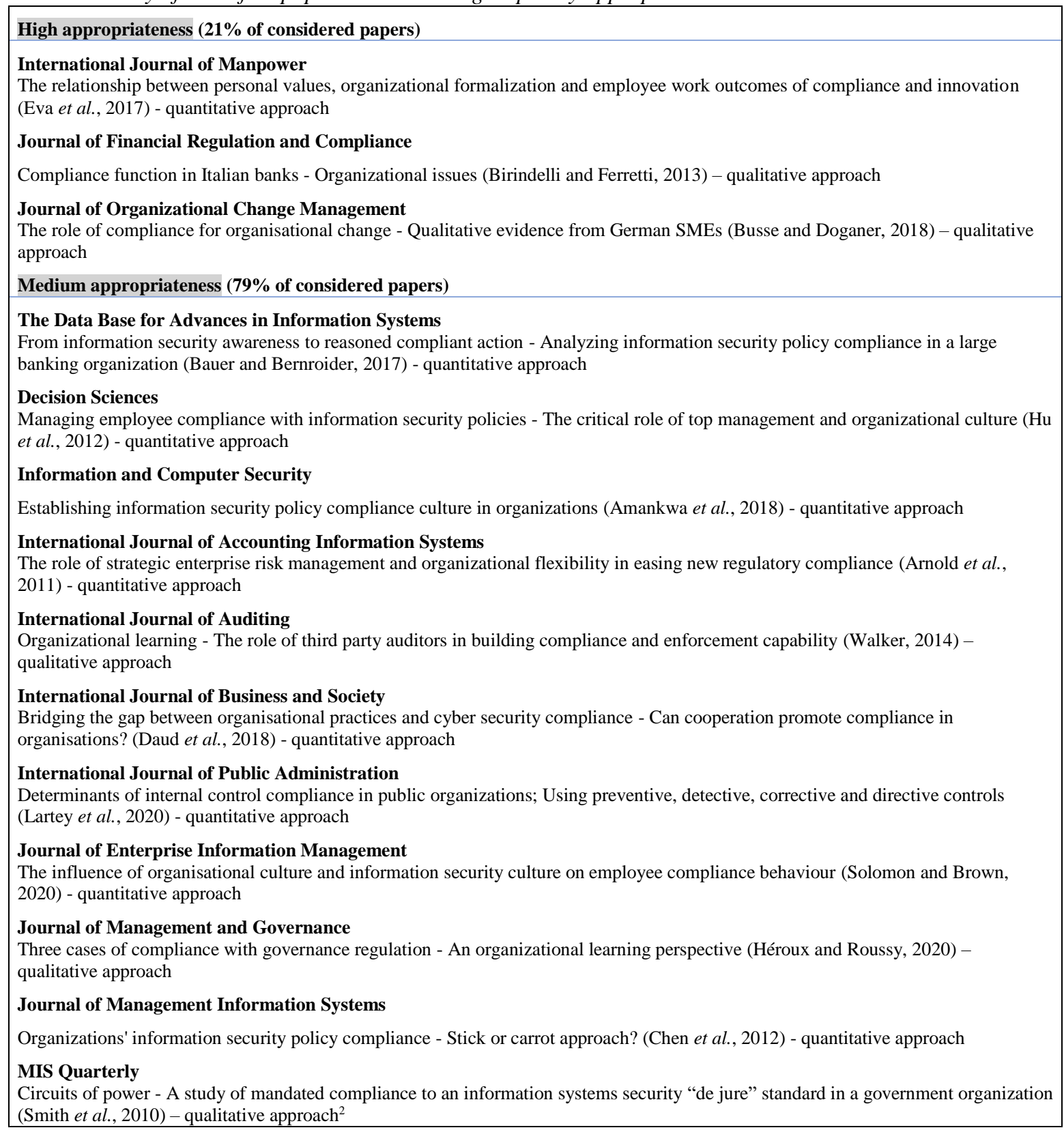

Source: Table created by the author

2 The canonical action research approach, used in that paper is considered as a qualitative approach. 97 
It is noticeable, that there are only few very relevant papers, which show a small research contribution to the success factors of compliance in organizations. As mentioned above, some positive influencing factors were identified in the context of information security, which were also examined with medium relevance. They represent the majority of the papers in this medium category. Neither a prioritized journal nor a prioritized author can be recognized, which once again points out the low level of research on organizational enablers of compliance. Figure 3 represents the findings regarding the chronological order of the papers and the used research method of the papers. No strong increase of the topic can be identified in the relevant literature during the last ten years. In some years even no relevant paper could be found. The organizational promoters of compliance seem to have been studied more quantitatively than qualitatively. The qualitative research methods mainly include various types of interviews, while structural equation modeling is increasingly used as a quantitative method. The high number of quantitative studies ensures quality of the SLR, as relationships and effects have been empirically tested. At the same time, the qualitative approaches suggest that positively influencing factors of compliance in an organizational context still need to be identified through exploratory and interpretive approaches.

Figure 3: Overview of papers' chronological distribution and research method used

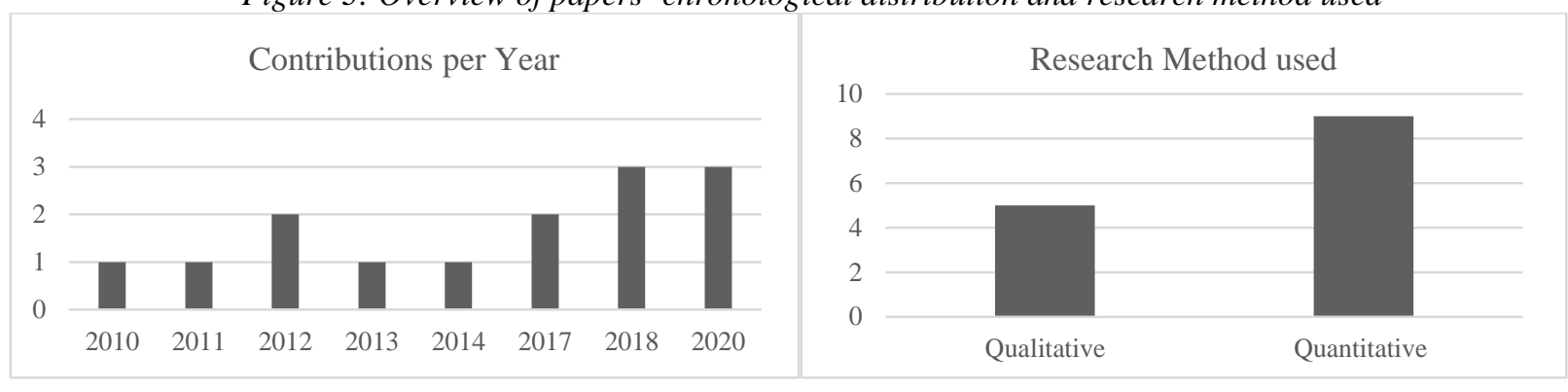

Source: Figure created by the author

\subsection{Content analysis}

The factors examined in the papers were assigned to the individual organizational categories of Waterman et al. (1980), which were described earlier in this study and enable a holistic approach to investigating the success factors of compliance in organizational environment. Depending on the interpretation, some aspects in literature could be assigned to more than one category, however for a better overview it has been decided to omit these details. In the following, the results for the individual categories are presented, thus making a significant contribution to answering the research question. The literature contributions for each organizational element are summarized in appendix B, table 3 .

When analyzing the various factors relating to structure, it becomes apparent that the aspect of cooperation seems to be of particular importance. Daud et al. (2018, p. 174) investigated the mediating function of cooperation considering organizational practices and cyber security compliance, which underlines cooperation with other employees as a structural factor that should not be neglected. Also synergistic cooperation with related departments such as internal audit or risk management seems to be important, but overlaps are inefficient and must be avoided (Birindelli and Ferretti, 2013, p. 236). The optimal organizational position of compliance seems 
to depend on various aspects, as Birindelli and Ferretti (2013, p. 235) state in their study in a banking environment. Applying the results of Walker (2014, p. 221), an appropriate addition of compliance structures might be the introduction of third party auditors, who can support the learning about compliance as an interface between regulators and companies. The empirical evidence against presumed correlations is also relevant. The results of Amankwa et al. (2018, p. 432) show that leadership does not necessarily strengthen employees' attitudes regarding information security policy compliance. An unexpected, non-significant moderating effect of formalization was also found in the study of Eva et al. (2017, p. 282) regarding conformity values and compliance behavior. These results suggest, that there may be other previously unstudied influences regarding these factors, which would need to be examined in detail to gain more knowledge in the area of compliance structure.

"System" is the category many relevant aspects can be assigned to. First, general characteristics of a compliance program seem to be necessary, such as "individualised, attractive, easy to handle (...) must improve processes to achieve efficiency and to increase business results (...) must be applicable to the entire value chain of a company" (Busse and Doganer, 2018, p. 347). Several further aspects could be summarized to three superordinate aspects: processes, control and involvement. Different kinds of processes like strategic enterprise risk management processes and implementation processes (Arnold et al., 2011) as well as structured processes, as investigated by Daud et al. (2018) with regard to cyber security compliance should be considered, when implementing compliance in an organization. Processes integrating internal and external channels for information acquisition should be taken into account to foster awareness, as examined by Bauer and Bernroider (2017) regarding information security. Also the existence of an control environment (Arnold et al., 2011) or the certainty of control (Chen et al., 2012) seems to support compliance implementation or intention. However the moderating effect of certainty of control seems not to be significant for the impact of reward on the intention to comply with security policies (Chen et al., 2012, p. 177). Reward and punishment will be further discussed in category "staff", however this fact already shows the interdependence of the different aspects. When it comes to control, different types of control may be applied, in particular preventive controls seem especially effective for certain environments to improve compliance, however should be supported by detective controls (Lartey et al., 2020, p. 720). A further particularly interesting aspect seems the involvement in creating compliance measures and processes and its implementation, as shown by the results of Busse and Doganer (2018) and Amankwa et al. (2018), what shows how important it is to consider the people that have to comply, also during the development and implementing phase.

Organizational skills, such as organizational flexibility (Arnold et al., 2011), or awareness, as examined by Bauer and Bernroider (2017) in the context of information security, are found to be important aspects that arise in connection with other factors and impact relations. Furthermore, Héroux and Roussy (2020) provide hints, that organizational learning may help implementing compliance, which should thereof be regarded as an important organizational capability.

The connection between compliance and strategy was also noted in the literature examined. An important and equally simple factor to consider represents the communication of easy to understand visions regarding compliance (Busse and Doganer, 2018, p. 347). Further aspects, which can be assigned to the category of strategy, can be summarized as resources and adjustment. 
The investment in relevant areas, as identified by Daud et al. (2018) in the context of cyber security as well as the right allocation of resources (Smith et al., 2010) seem to be important strategic factors. Closely related to this is a strategy and implementation adapted to the respective (subunit) size (Smith et al., 2010).

"Style" obviously plays an important role in the context of organizational compliance enablers. General culture and group norms (Smith et al., 2010) as well as different types of cultures such as organizational culture (Hu et al., 2012; Solomon and Brown, 2020), supportive organizational culture (Amankwa et al., 2018), or information security culture (Solomon and Brown, 2020), all in turn consisting of different components and characteristics, have been studied with regard to compliance in different contexts. All in all, the contributions in literature show, that culture should be regarded as a central and influential organizational aspect. An active top management, which can be expressed through commitment (Daud et al., 2018; Smith et al., 2010), participation (Hu et $a l ., 2012$ ) or input (Smith et al., 2010) represents a significant part of the literature examined. This contrasts with the investigation regarding compliance leadership (Amankwa et al., 2018) discussed in category structure and could indicate that the conviction and commitment of the management or leadership may play a more important role than its mere structural existence.

Category "staff" appears to be a well discussed organizational aspect in literature. Especially intrinsic aspects of the persons, who are supposed to behave compliantly play a central role. Conformity values (Eva et al., 2017), attitudes (Amankwa et al., 2018; Bauer and Bernroider, 2017; Hu et al., 2012), behavior intentions (Amankwa et al., 2018; Bauer and Bernroider, 2017) different types of norms (Bauer and Bernroider, 2017; Hu et al., 2012) were examined as important influencing factors. Another already in category "structure" mentioned interesting aspect regarding staff was identified by Chen et al. (2012), examining the use of reward and punishment as factors influencing compliance intentions, which provides an interesting starting point for a comprehensive enforcement system.

The results show, that various influencing factors could be found in literature for almost every organizational area. Considering the aspects identified in literature, a division into hard and soft organizational factors seems to be useful for further interpretations of their influence on compliance. 
Figure 4: Conceptual framework for organizational success factors of compliance as a result of the SLR

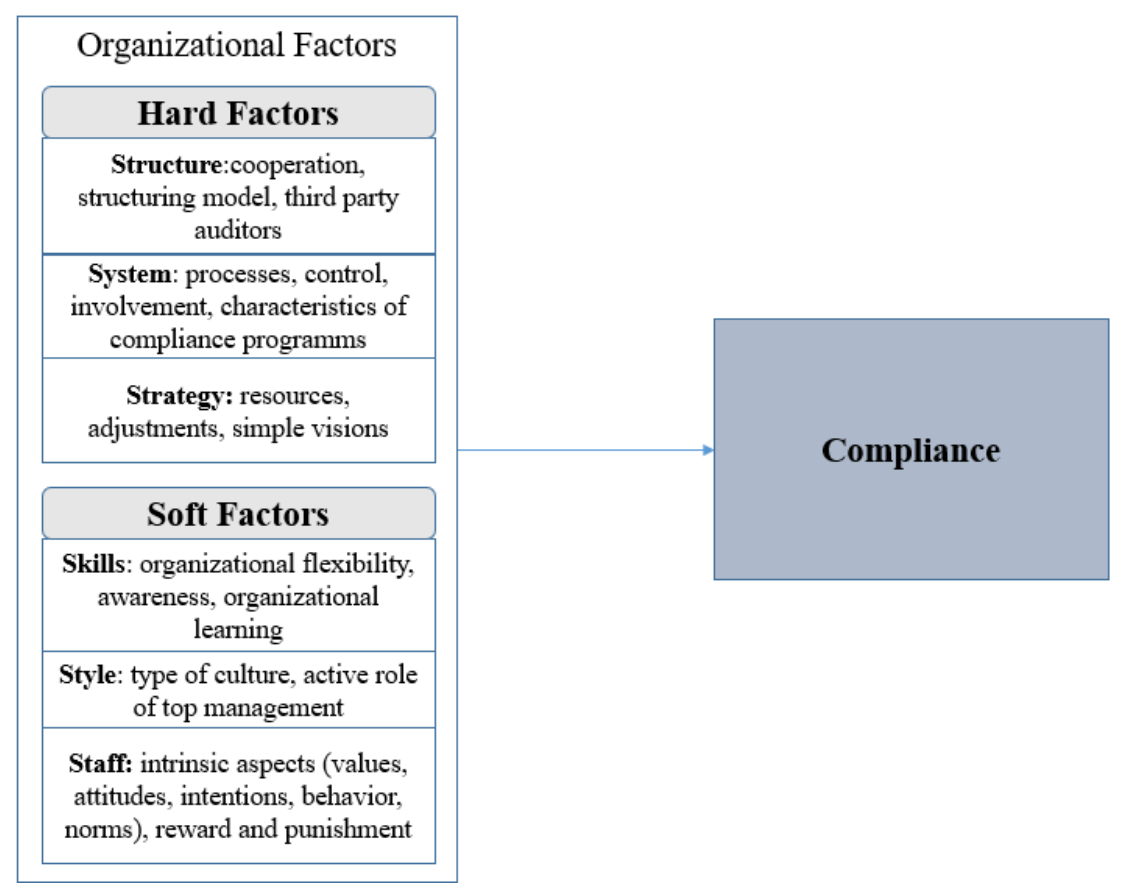

Source: Figure created by the author

Only for the area of superordinate goals no aspects could be assigned, which probably suggests that compliance does not play a superordinate role for organizations, which could be further investigated in another research framework. The organizational factors described above contribute to answering the research question but should rather be seen as starting points for further research. Most papers insist on further research of their results with other or larger samples (e.g. Amankwa et al., 2018, p. 434; Arnold et al., 2011, p. 187; Busse and Doganer, 2018, p. 347; Hu et al., 2012, p. 639). As compliance was examined in different contexts, there are important hints in the papers, such as being careful with conclusions of the results to other organizations (Bauer and Bernroider, 2017, p. 59), as for a generalizability of the results found in a study, further organizations in different contexts need to be examined (Chen et al., 2012, p. 180) and different results could be obtained in other research environments (Amankwa et al., 2018, p. 434). Based on their results, research focus and contexts, some papers also mention specific starting points for further research (e.g. Amankwa et al., 2018, p. 433; Chen et al., 2012, p. 180; Eva et al., 2017, p. 283; Hu et al., 2012, p. 648-649; Solomon and Brown, 2020, n.p.). Particularly interesting were the future research suggestions of Eva et al. (2017, p. 283) to investigating situational factors (e.g. type of organization, environment, strategy). This might suggest that such factors may play a moderating role on the effect of enablers on compliance. Accordingly, literature identifies a range of research needs, which illustrates the general ongoing research of compliance success factors in organizations. 


\section{Discussion}

The results of this SLR show, that there are already various starting points for success factors of compliance in the individual areas of an organization. Summarizing the specific factors show, that organizations could take a comprehensive approach to holistically implement success factors in organizational areas and thus achieve more effective compliance management. Particularly the factor "human" seems to be of importance, as shown by the contributions in the "soft" factors. Finally, organizations can easily implement hard factors such as structures, processes, controls or security investments, and also a strategy can be changed in general, but the intrinsic factors of the employees, who should behave compliantly, seem to be of particular importance, as well as aspects such as culture and organizational skills, which are slow and difficult to change or develop. An important implication of this paper is, that there are various organizational success factors, which could be considered as "quick fixes" for better compliance, including the aspects of the categories "structure", "system" and "strategy", as they could be implemented independently. However, for long-term success in compliance, the focus should lie on the categories "style", "staff" and "skills", which shows how important it is to employ the right people with the right skills and intrinsic attitudes towards compliance. This conclusion was also made by Eva et al. (2017, p. 284), who further suggest to use analysis tools to identify employees' values. This has a significant impact on human resources departments, which could contribute to the success of compliance through the selection and even development of employees. Summarizing the further research suggestions in literature show, that further research in bigger contexts is also necessary to obtain more validity and several unconsidered cause-effect relationships need to be further analyzed.

It is also important to point out the limitations of this paper. The results of the SLR were all developed in specific contexts, samples, and complex, often non-direct impact investigations of different types of compliance, which is why the results are not easily transferable to every organization and every type of compliance. Compliance in the context of information security seems to be well researched, also with reference to some organizational aspects and was therefore included in the SLR, but the knowledge about the transfer of these insights to general, corporate compliance in organizations is missing. At the same time, the qualitative included approaches in the SLR suggest, that positively influencing factors of compliance in an organizational context still need to be identified through further exploratory and interpretive approaches, which need to be quantitatively tested for stronger validity.

These limitations lead to the need for further research, not only on the specific compliance success factors, but also on the overall understanding of their interactions and effectiveness. The factors identified through the SLR can only represent initial approaches for organizational success factors of compliance and thus need to be further analyzed in a controlled and constant environment of corporate compliance, applying a concrete and delimited definition of compliance. The identified factors should be first qualitatively further examined, e.g. via expert interviews, in order to identify the most important factors for each organizational area. The hypothesized causal relationships should then be tested using quantitative analyses such as structural equation modeling. More intensive research on the soft factors, especially culture and intrinsic factors of the employees, is needed. Further investigations could shed light on, whether the soft factors can be ascribed a special role compared to the other factors. In addition, there were no results in the literature, that could be assigned to the category "superordinate goals". Further research is necessary to determine 
whether this category is not important for compliance or whether this aspect has not been considered yet. All in all, this paper is a starting point for many further studies and insights into the complex structure of corporate compliance and its enablers.

\section{References}

Amankwa, E., Loock, M. and Kritzinger, E. (2018), "Establishing information security policy compliance culture in organizations", Information \& Computer Security, Vol. 26 No. 4, pp. 420-436.

Amponsah, O., Håkan, V., Schou, T.W., Braimah, I. and Abaidoo, R.C. (2016), "The impact of farmers' participation in field trials in creating awareness and stimulating compliance with the World Health Organization's farm-based multiple-barrier approach", Environment, Development and Sustainability, Vol. 18 No. 4, pp. 1059-1079.

Araújo Marques, J., Sousa, P. and Teixeira, G. (2020), “Tax audits as a path to tax compliance in Portugal", European Journal on Criminal Policy and Research, Vol. 26 No. 4, pp. 457-479.

Arnold, V., Benford, T., Canada, J. and Sutton, S.G. (2011), "The role of strategic enterprise risk management and organizational flexibility in easing new regulatory compliance", International Journal of Accounting Information Systems, Vol. 12 No. 3, pp. 171-188.

Baharuddin, S.A. and Ismail, R.M. (2018), "Halal compliance impact on organizational performance. The role of religiosity", International Journal of Supply Chain Management, Vol. 7 No. 5, pp. 455-460.

Baier, C., Beckmann, M. and Heidingsfelder, J. (2020), "Hidden allies for value chain responsibility? A system theory perspective on aligning sustainable supply chain management and trade compliance", International Journal of Physical Distribution \& Logistics Management, Vol. 50 No. 4, pp. 439-456.

Barlow, J.B., Warkentin, M., Ormond, D. and Dennis, A.R. (2018), “Don’t Even Think About It! The Effects of Antineutralization, Informational, and Normative Communication on Information Security Compliance", Journal of the Association for Information Systems, Vol. 19 No. 8, pp. 689-715.

Bauer, S. and Bernroider, E.W.N. (2017), "From Information Security Awareness to Reasoned Compliant Action. Analyzing Information Security Policy Compliance in a Large Banking Organization", The DATA BASE for Advances in Information Systems, Vol. 48 No. 3, pp. 4468.

Birindelli, G. and Ferretti, P. (2013), “Compliance function in Italian banks. Organizational issues", Journal of Financial Regulation and Compliance, Vol. 21 No. 3, pp. 217-240.

Bulgurcu, B., Cavusoglu, H. and Benbasat, I. (2010), "Information Security Policy Compliance. An Empirical Study of Rationality-Based Beliefs and Information Security Awareness", MIS Quarterly, Vol. 34 No. 3, pp. 523-548.

Burdon, W.M. and Sorour, M.K. (2020), "Institutional Theory and Evolution of 'A Legitimate' Compliance Culture. The Case of the UK Financial Service Sector", Journal of Business Ethics, Vol. 162 No. 1, pp. 47-80. 
Busse, R. and Doganer, U. (2018), "The role of compliance for organisational change. Qualitative evidence from German SEMs”, Journal of Organizational Change Management, Vol. 31 No. 2, pp. 334-351.

Celis, N.J. (2018), "Compliance theory. A case study approach in understanding organizational commitment”, DLSU Business and Economics Review, Vol. 27 No. 2, pp. 88-118.

Chen, Y., Ramamurthy, K. and Wen, K.-W. (2012), "Organizations' Information Security Policy Compliance. Stick or Carrot Approach?”, Journal of Management Information Systems, Vol. 29 No. 3, pp. 157-188.

D’Attoma, J.W., Volintiru, C. and Malézieux, A. (2020), “Gender, Social Value Orientation, and Tax Compliance”, CESifo Economic Studies, Vol. 66 No. 3, pp. 265-284.

Daud, M., Rasiah, R., George, M., Asirvatham, D. and Thangiah, G. (2018), "Bridging the gap between organisational practices and cyber security compliance. Can cooperation promote compliance in organisations?", International Journal of Business \& Society, Vol. 19 No. 1, pp. 161-180.

Dávalos, J., Claure, M. and Leytón, A. (2020), “The gender effects of the minimum wage under weak compliance with labour regulations. The case of Bolivia", Applied Economics, Vol. 52 No. 47, pp. 5115-5128.

Enciso, S., Milikin, C. and O’Rourke, J.S. (2017), "Corporate culture and ethics. From words to actions", Journal of Business Strategy, Vol. 38 No. 6, pp. 69-79.

Eva, N., Prajogo, D. and Cooper, B. (2017), "The relationship between personal values, organizational formalization and employee work outcomes of compliance and innovation", International Journal of Manpower, Vol. 38 No. 2, pp. 274-287.

Farooq, O. and Pashayev, Z. (2020), "Shariah compliance and information transmission. Evidence from an emerging market", Journal of Islamic Accounting and Business Research, Vol. 11 No. 8, pp. 1583-1597.

Feng, G., Zhu, J., Wang, N. and Liang, H. (2019), "How Paternalistic Leadership Influences IT Security Policy Compliance. The Mediating Role of the Social Bond", Journal of the Association for Information Systems, Vol. 20 No. 11, pp. 1650-1691.

Fink, A. (2020), Conducting research literature reviews: From the internet to paper, 5 th. ed. Los Angeles: Sage.

Fotaki, M., Lioukas, S. and Voudouris, I. (2020), "Ethos is Destiny. Organizational Values and Compliance in Corporate Governance", Journal of Business Ethics, Vol. 166 No. 1, pp. 1937.

Handayani, Y.D. and Ibrani, E.Y. (2019), “Corporate Governance Application, Audit Quality and Audit Report Lag. The Moderating Role of Law Compliance", International Journal of Financial Research, Vol. 10 No. 4, pp. 164-171.

Héroux, S. and Roussy, M. (2020), "Three cases of compliance with governance regulation. An organizational learning perspective", Journal of Management and Governance, Vol. 24 No. 2, pp. 449-479. 
Hu, Q., Dinev, T., Hart, P. and Cooke, D. (2012), "Managing Employee Compliance with Information Security Policies. The Critical Role of Top Management and Organizational Culture", Decision Sciences, Vol. 43 No. 4, pp. 615-659.

Ismail, A.M., Ismail, C.R., Sulaiman, S. and Daud, D. (2020), "Corporate Governance and Firm Risk. Evidence from Malaysian Shariah Compliance Companies", Humanities and Social Sciences Letters, Vol. 8 No. 2, pp. 169-193.

Jajja, M.S.S., Asif, M., Montabon, F. and Chatha, K.A. (2019), "Buyer-supplier relationships and organizational values in supplier social compliance", Journal of Cleaner Production, Vol. 214, pp. 331-344.

Jensen, M.C. (1983), "Organization theory and methodology", The Accounting Review, Vol. 58 No. 2, pp. 319-339.

Johannsen, A., Kant, D. and Creutzburg, R. (2020), "Measuring IT security, compliance and data governance within small and medium-sized IT enterprises", Electronic Imaging, Vol. 2020 No. 3, 252-1-252-11.

Khan, K.S., Kunz, R., Kleijnen, J. and Antes, G. (2003), "Five Steps to Conducting a Systematic Review", Journal of the Royal Society of Medicine, Vol. 96 No. 3, pp. 118-121.

Lartey, P.Y., Kong, Y., Bah, F.B.M., Santosh, R.J. and Gumah, I.A. (2020), “Determinants of Internal Control Compliance in Public Organizations; Using Preventive, Detective, Corrective and Directive Controls", International Journal of Public Administration, Vol. 43 No. 8, pp. 711-723.

Li, J., Wang, X. and Wu, Y. (2020), "Can government improve tax compliance by adopting advanced information technology? Evidence from the Golden Tax Project III in China", Economic Modelling, Vol. 93, pp. 384-397.

Massaro, M., Dumay, J. and Guthrie, J. (2016), "On the shoulders of giants. Undertaking a structured literature review in accounting", Accounting, Auditing \& Accountability Journal, Vol. 29 No. 5, pp. 767-801.

Mustapha, A.M., Arogundade, O.T., Misra, S., Damasevicius, R. and Maskeliunas, R. (2020), "A systematic literature review on compliance requirements management of business processes", International Journal of System Assurance Engineering and Management, Vol. 11 No. 3, pp. 561-576.

Nielsen, V.L. and Parker, C. (2012), "Mixed Motives. Economic, Social, and Normative Motivations in Business Compliance", Law \& Policy, Vol. 34 No. 4, pp. 428-462.

Okoli, C. (2015), "A Guide to Conducting a Standalone Systematic Literature Review", Communications of the Association for Information Systems, Vol. 37 No. 43, pp. 879-910.

Paliszkiewicz, J. (2019), "Information Security Policy Compliance. Leadership and Trust", Journal of Computer Information Systems, Vol. 59 No. 3, pp. 211-217.

Parker, C. and Nielsen, V.L. (2009), "Corporate Compliance Systems. Could They Make Any Difference?”, Administration \& Society, Vol. 41 No. 1, pp. 3-37.

Pike, K. (2020), "Voice in Supply Chains. Does the Better Work Program Lead to Improvements in Labor Standards Compliance?”, ILR Review, Vol. 73 No. 4, pp. 913-938. 
Quick, R. and Sayar, S. (2020), "The impact of assurance on compliance management systems on bank directors' decisions", International Journal of Auditing, pp. 1-21.

Robbins, B. and Kiser, E. (2020), "State coercion, moral attitudes, and tax compliance. Evidence from a national factorial survey experiment of income tax evasion", Social science research, Vol. 91, p. 102448.

Satt, H., Bendriouch, F.Z. and Nechbaoui, S. (2020), "The impact of Shariah finance compliance level on the cost of debt", Journal of Islamic Accounting and Business Research, Vol. 11 No. 6, pp. 1211-1226.

Smith, S., Winchester, D., Bunker, D. and Jamieson, R. (2010), "Circuits of Power. A Study of Mandated Compliance to an Information Systems Security" De Jure" Standard in a Government Organization", MIS Quarterly, Vol. 34 No. 3, pp. 463-486.

Solomon, G. and Brown, I. (2020), "The influence of organisational culture and information security culture on employee compliance behaviour", Journal of Enterprise Information Management, ahead-of-print No. ahead-of-print, p. 51.

Süsi, V. and Lukason, O. (2019), "Corporate governance and failure risk. Evidence from Estonian SME population”, Management Research Review, Vol. 42 No. 6, pp. 703-720.

Tirole, J. (2001), “Corporate Governance”, Econometrica, Vol. 69 No. 1, pp. 1-35.

Tsalavoutas, I., Tsoligkas, F. and Evans, L. (2020), “Compliance with IFRS mandatory disclosure requirements. A structured literature review", Journal of International Accounting, Auditing and Taxation, Vol. 40, p. 100338.

Walker, C. (2014), "Organizational Learning. The Role of Third Party Auditors in Building Compliance and Enforcement Capability”, International Journal of Auditing, Vol. 18 No. 3, pp. 213-222.

Waterman, R.H., Peters, T.J. and Phillips, J.R. (1980), "Structure is not organization", Business Horizons, Vol. 23 No. 3, pp. 14-26.

Winter, S.C. and May, P.J. (2001), "Motivation for Compliance with Environmental Regulations", Journal of Policy Analysis and Management, Vol. 20 No. 4, pp. 675-698.

Woschank, M., Rauch, E. and Zsifkovits, H. (2020), “A Review of Further Directions for Artificial Intelligence, Machine Learning, and Deep Learning in Smart Logistics", Sustainability, Vol. 12 No. 9, p. 3760.

Xiao, Y. and Watson, M. (2019), "Guidance on Conducting a Systematic Literature Review", Journal of Planning Education and Research, Vol. 39 No. 1, pp. 93-112.

Zulfikar, R., Lukviarman, N., Suhardjanto, D., Ismail, T., Dwi Astuti, K. and Meutia, M. (2020), "Corporate Governance Compliance in Banking Industry. The Role of the Board", Journal of Open Innovation: Technology, Market, and Complexity, Vol. 6 No. 4, p. 137. 


\section{Appendix A}

Search string: (TITLE(Compliance) AND TITLE(literature review)) AND ( LIMIT-TO (SUBJAREA,"BUSI" ) OR LIMIT-TO ( SUBJAREA,"ECON" ) )

Export Date: 23 Dec 2020, Source: Scopus

Results:

1) Tsalavoutas, I., Tsoligkas, F., Evans, L.

Compliance with IFRS mandatory disclosure requirements: A structured literature review (2020) Journal of International Accounting, Auditing and Taxation, 40, art. no. 100338.

2) Mustapha, A.M., Arogundade, O.T., Misra, S., Damasevicius, R., Maskeliunas, R.

A systematic literature review on compliance requirements management of business processes

(2020) International Journal of Systems Assurance Engineering and Management, 11 (3), pp. 561-576.

3) Mustapha, Z., Kunhibava, S.B., Muneeza, A.

Legal and Sharī'ah non-compliance risks in Nigerian Islamic finance industry: a review of the literature

(2020) International Journal of Law and Management.

4) Newman, W., Mwandambira, N., Charity, M., Ongayi, W.

Literature review on the impact of tax knowledge on tax compliance among small medium enterprises in a developing country (2018) International Journal of Entrepreneurship, 22 (4).

5) Newman, W., Mwandambira, N., Charity, M., Ongayi, W.

Literature review on the impact of tax knowledge on tax compliance among small medium enterprises in a developing country (2018) Journal of Legal, Ethical and Regulatory Issues, 22 (4), 15 p.

6) Carvalho, C., Rodrigues, A.M., Ferreira, C.

Goodwill and Mandatory Disclosure Compliance: A Critical Review of the Literature (2016) Australian Accounting Review, 26 (4), pp. 376-389. 


\section{Appendix B}

Table 3: Literature contributions for each organizational element

\begin{tabular}{|l|ll|}
\hline \multicolumn{3}{|c|}{ Structure } \\
\hline cooperation & $\bullet$ & $\begin{array}{l}\text { Birindelli and Ferretti, 2013; } \\
\text { Daud } \text { et al., 2018 }\end{array}$ \\
\hline compliance structuring model/program & $\bullet$ & Birindelli and Ferretti, 2013 \\
\hline third party auditors & $\bullet$ & Walker, 2014 \\
\hline leadership (not supported) & $\bullet$ & Amankwa et al., 2018 \\
\hline $\begin{array}{l}\text { organizational formalization } \\
\text { (moderating effect not supported) }\end{array}$ & $\bullet$ & Eva et al., 2017 \\
\hline
\end{tabular}

\begin{tabular}{|c|c|c|}
\hline \multicolumn{3}{|c|}{ System } \\
\hline processes & $\begin{array}{ll}- & \text { strategic ERM processes } \\
\text { - } & \text { implementation processes } \\
\text { - } & \text { structured security processes } \\
\text { - } & \text { internal and external channel use for } \\
& \text { information acquisition }\end{array}$ & $\begin{array}{ll}\text { - } & \text { Arnold } \text { et al., 2011; } \\
\text { - } & \text { Arnold } \text { et al., 2011; } \\
\text { - } & \text { Daud } \text { et al., } 2018 \\
\text { - } & \text { Bauer and Bernroider, } 2017\end{array}$ \\
\hline control & $\begin{array}{ll}\text { - } & \text { control environment } \\
\text { - } & \text { certainty of control } \\
& \text { types of control (preventive, detective, } \\
& \text { corrective and directive) }\end{array}$ & $\begin{array}{ll}\text { - } & \text { Arnold } \text { et al., 2011; } \\
\text { - } & \text { Chen } \text { et al., 2012 } \\
& \text { Lartey et al., } 2020\end{array}$ \\
\hline involement & $\begin{array}{ll}\text { - } & \text { employee involvement } \\
\text { - } & \text { end-user involvement } \\
\end{array}$ & $\begin{array}{ll}\text { - } & \text { Busse and Doganer, 2018; } \\
\text { - } & \text { Amankwa } \text { et al., } 2018 \\
\end{array}$ \\
\hline $\begin{array}{l}\text { characteristics of } \\
\text { compliance programs }\end{array}$ & & - $\quad$ Busse and Doganer, 2018 \\
\hline
\end{tabular}

\begin{tabular}{|l|ll|ll|}
\hline \multicolumn{4}{|c|}{ Strategy } \\
\hline resources & $\bullet$ & $\begin{array}{l}\text { security investment } \\
\text { resource allocation }\end{array}$ & $\bullet$ & $\begin{array}{l}\text { Daud } \text { et al., 2018 } \\
\text { Smith } \text { et al., 2010 }\end{array}$ \\
\hline adjustment & $\bullet$ & $\begin{array}{l}\text { strategy considering subunit size of } \\
\text { organization } \\
\text { implementation considering agency size }\end{array}$ & $\bullet$ & Smith et al., 2010 \\
\hline simple visions & & & Busse and Doganer, 2018 \\
\hline
\end{tabular}

\begin{tabular}{|l|ll|}
\hline \multicolumn{3}{|c|}{ Skills } \\
\hline organizational flexibility & $\bullet$ & Arnold et al., 2011 \\
\hline (Information Security) awareness & $\bullet$ & Bauer and Bernroider, 2017 \\
\hline $\begin{array}{l}\text { organizational learning (learning } \\
\text { experience) }\end{array}$ & $\bullet$ & Héroux and Roussy, 2020 \\
\hline
\end{tabular}




\begin{tabular}{|l|ll|l|}
\hline \multicolumn{2}{|c|}{ Style } \\
\hline type of culture & $\bullet$ & $\begin{array}{l}\text { supportive organizational culture } \\
\text { organizational culture }\end{array}$ & $\begin{array}{l}\text { Amankwa } \text { et al., 2018 } \\
\bullet\end{array}$ \\
& $\bullet \begin{array}{l}\text { Hu } \text { et al., 2012; Solomon and } \\
\text { Brown, 2020 }\end{array}$ \\
& $\bullet \begin{array}{l}\text { Information Security culture } \\
\text { Smith } \text { et al., 2010 } \\
\text { Solomon and Brown, 2020 }\end{array}$ \\
\hline $\begin{array}{l}\text { active role of top } \\
\text { management }\end{array}$ & $\bullet \begin{array}{l}\text { top management commitment } \\
\text { top management participation } \\
\text { senior management input and } \\
\text { commitment }\end{array}$ & $\bullet \begin{array}{l}\text { Daud } \text { et al., 2018 } \\
\text { Hu } \text { et al., 2012 } \\
\text { Smith } \text { et al., 2010 }\end{array}$ \\
\hline
\end{tabular}

\begin{tabular}{|l|ll|l|}
\hline \multicolumn{2}{|c|}{ Staff } \\
\hline $\begin{array}{l}\text { intrinsic aspects (values, } \\
\text { attitudes, intentions, } \\
\text { behavior, norms) }\end{array}$ & $\bullet$ & $\begin{array}{l}\text { conformity values } \\
\text { attitudes }\end{array}$ & $\begin{array}{l}\text { Eva } \text { et al., 2017 } \\
\text { Amankwa } \text { et al., 2018; Bauer and } \\
\text { Bernroider, 2017; Hu } \text { et al., 2012 } \\
\text { Amankwa } \text { et al., 2018; Bauer and } \\
\text { Bernroider, 2017 }\end{array}$ \\
& $\bullet \begin{array}{l}\text { Information Security policy compliance } \\
\text { behavioral intention; intention for } \\
\text { compliant information security behavior }\end{array}$ & $\begin{array}{l}\text { social norms and neutralization } \\
\text { techniques (personal norms); subjective } \\
\text { norms } \\
\text { perceived behavioral control over } \\
\text { compliance }\end{array}$ & $\begin{array}{l}\text { Bauer and Bernroider, 2017; Hu } \\
\text { et al., 2012 }\end{array}$ \\
\hline reward and punishment & & Hu et al., 2012 \\
\hline
\end{tabular}

Source: Table created by the author 